\title{
Kearifan Lokal Budaya Jawa Dalam Film “Tilik”
}

\section{Local Wisdom of Javanese Culture in the Film "Tilik"}

\author{
Ilma Saakinah Tamsil1)* \\ 1)Program Studi Ilmu Komunikasi, Fakultas Ilmu Sosial Dan Ilmu Politik, Universitas Medan \\ Area, Indonesia \\ Diterima: 22 Juli 2021; Disetujui: 20 Oktober 2021; Dipublish: Dipublish: 31 Oktober 2021 \\ *Coresponding Email: ilmapayi@gmail.com
}

\begin{abstract}
Abstrak
Tilik merupakan warisan asli budaya Jawa yang mengangkat pola keseharian masyarakat Indonesia pada umumnya. Tujuan penulisan untuk menjabarkan bagaimana kearifan lokal budaya jawa di dalam film Tilik. Penelitian ini menggunakan deskriptif kualitatif menggunakan konsep triadic Charles Sanders Peirce yang kemudian diaplikasikan menjadi konsep matter of expression di dalam film melalui adegan, karakter, bahasa dan dialog yang ditampilkan selama 32 menit. Hasilnya ditemukan kearifan lokal budaya Jawa khususnya masyarakat pedesaan melalui kebiasaan yang sering dihadapi oleh masyarakat dalam kesehariannya. Budaya Tilik yang dilakukan ibu-ibu Jawa ini sebagai bentuk toleransi serta rasa kebersamaan antar warga melalui sikap teposliro. Pemaparan simbol Jawa terlihat dari karakter pemeran film, setting keindahan alam Kecamatan Dlingo, Bantul, Yogyakarta, suasana jalan raya yang dilewati truk, keindahan sawah, serta Jawa Ngoko masyarakat desa sangat terasa melalui dialog yang digunakan di dalam keseluruhan film namun terdapat nilai-nilai budaya yang dikonstruk dan diproduksi sehingga memberikan penilaian bahwa pemaparan wanita Jawa yang disajikan di dalam film sedikit berlebihan menjadi proses penandaan, praktik yang membuat suatu hal menjadi memiliki makna. Kesimpulan yang diperoleh bahwa kearifan lokal budaya Jawa khususnya masyarakat pedesaan melalui kebiasaan yang sering dihadapi oleh masyarakat dalam kesehariannya.
\end{abstract}

\section{Kata Kunci: film; Kearifan Lokal Jawa; Semiotika.}

\section{Abstract}

Tilik is an original Javanese cultural heritage that elevates the daily patterns of Indonesian society in general. The purpose of writing is to describe how the local wisdom of Javanese culture is in the Tilik film. This study uses a qualitative descriptive study using Charles Sanders Peirce's triadic concept which is then applied to the concept of matter of expression in the film through scenes, characters, language and dialogue that are displayed for 32 minutes. The results found local wisdom of Javanese culture, especially rural communities through habits that are often faced by people in their daily lives. The Tilik culture carried out by Javanese women is a form of tolerance and a sense of togetherness among residents through the attitude of teposliro. The presentation of Javanese symbols can be seen from the characters of the film actors, the setting of the natural beauty of Dlingo District, Bantul, Yogyakarta, the atmosphere of the highway passed by trucks, the beauty of the rice fields, and the Javanese Ngoko of the village community can be felt through the dialogues used in the entire film, but there are cultural values. which is constructed and produced so as to provide an assessment that the exposure of Javanese women presented in the film is a bit exaggerated to be a process of marking, a practice that makes something meaningful. The conclusion is that the local wisdom of Javanese culture, especially rural communities, is through habits that are often faced by people in their daily lives

Keywords: Film; Javanese Local Wisdom; Semiotic.

How to Cite: Tamsil, Ilma Saakinah. (2021). Kearifan Lokal Budaya Jawa Dalam Film "Tilik". 7 (2): 152-165 


\section{PENDAHULUAN}

Film

merupakan

gambaran

kehidupan di mana seringkali menceritakan ulang kehidupan yang selama ini terjadi di dalam masyarakat. Mulai dari bahasa, budaya, adat istiadat yang ditampilkan di dalam film dianggap sebagai cerminan masyarakat. Film dibuat sebaik mungkin sehingga dapat diterima dan menarik perhatian masyarakat (Danesi, 2010). Banyak pembuat film di Indonesia mengangkat nilai-nilai budaya di dalam unsur produksi filmnya. Ide yang disampaikan disesuaikan karena Indonesia memiliki ragam nilai budaya sebagai kearifan lokal sehingga dapat menjadi sekaligus alat promosi budaya Indonesia.

Kearifan lokal merupakan identitas budaya masyarakat berupa nilai, norma, etika, kepercayaan, adat istiadat, dan aturan khusus yang diberlakukan oleh suatu kebudayaan masyarakat. Kearifan lokal adalah adat dan kebiasaan yang telah menjadi tradisi dilakukan oleh sekelompok masyarakat secara turun-temurun yang hingga saat ini masih dipertahankan keberadaannya oleh masyarakat hukum adat tertentu di daerah tertentu (Alfian, 2013). Film Tilik, terdapat unsur kearifan lokal yang menampilkan identitas budaya pada alur ceritanya yaitu di sepanjang film menggunakan dialog bahasa Jawa serta karakter yang kuat dan kental pada budaya Jawa melalui kebiasaan menjenguk (Tilik).

Film Tilik merupakan salah satu film pendek Yogyakarta arahan Wahyu Agung Prasetyo yang lolos kurasi dana istimewa Dinas Kebudayaan Provinsi Daerah Istimewa Yogyakarta. Film ini awalnya sudah diproduksi pada 2018, namun masyarakat dapat menyaksikan film ini melalui Youtube pada 17 Agustus 2020. Film Tilik mendapatkan penghargaan kategori Film Pendek Terpilih Piala Maya 2018, menjadi Official Selection JogjaNetpac Asian Film Festival (JAFF) 2018, serta menjadi Official Selection World Cinema Amsterdam 2019. Sejak diunggah di Youtube, film Tilik berhasil ditonton lebih dari 2,7 juta pengguna dalam kurun waktu tiga hari. Penggunakan teori konsep triadic Charles Sanders Peirce untuk mengambarkan tujuan penulisan ini bagaimana Kearifan Lokal Budaya Jawa di dalam Film Tilik?

Film sebagai media komunikasi merupakan kombinasi pesan yang ingin disampaikan sutradara. Sebagai penonton, harus mampu menyaring pesan di dalam film karena tidak semua film memiliki nilai positif. Hal ini menjadi sebuah tantangan masyarakat untuk cerdas memilih tontonan yang berkualitas agar tidak terjebak dalam realitas dan lingkungan tiruan dari media yang kompleks. Salah 
satu media massa yang berperan dalam pembelajaran budaya adalah film.

Menurut Hall (2002) melalui representasi, suatu makna diproduksi dan dipertukarkan antar anggota masyarakat. Jadi dapat dikatakan, representasi adalah satu cara memproduksi makna. Representasi adalah proses produksi pertukaran makna antara manusia atau antar budaya yang menggunakan gambar, simbol dan bahasa. Bahasa pula menjadi budaya yang sering digunakan dalam produksi dan pertukaran makna melalui pengalaman-pengalaman yang terjadi di dalam masyarakat. Konsep budaya memiliki peran utama di dalam proses representasi maka, budaya adalah sistem representasi. Seseorang dikatakan berasal dari kebudayaan yang sama apabila hidup di tempat yang sama dan memiliki bahasa yang sama.

Representasi budaya berdasarkan kepada konstruksi media (terutama media massa) terhadap aspek realitas misalnya masyarakat, objek, peristiwa dan identitas budaya. Representasi dapat berbentuk kata-kata, tulisan dan film. Representasi tidak hanya melibatkan bagaimana identitas budaya dikonstruk di dalam film, tetapi juga dikonstruk di dalam proses produksi oleh masyarakat yang mengkonsumsi nilai-nilai budaya yang direpresentasikan dalam film. Selain tidak hanya mengkonstruksikan nilai-nilai budaya tertentu, film juga melihat bagaimana nilai-nilai diproduksi serta nilai-nilai tersebut diterima masyarakat yang menonton film. Maka setelah itu, proses representasi budaya terjadi.

Budaya adalah sebuah identitas dari suatu daerah karena di antara satu daerah dengan daerah yang lain memiliki kebudayaan dan cara menjalani kehidupan yang berbeda-beda pula. Kebudayaan merupakan hasil karya manusia yang diusahakan untuk kelangsungan hidup, keturunan dan kesejahteraan. Kebudayaan juga pengetahuan manusia yang kebenarannya diyakini masyarakat yang bersangkutan. Kebudayaan biasanya dilandasi oleh nilai-nilai moral setiap manusia sehingga menjadi sistem penilaian mengenai baik dan buruk, sesuatu yang berharga atau tidak dan sebagainya. Simbol pula memiliki kedudukan yang penting dalam perwujudan sebuah budaya pada dasarnya, unsur-unsur budaya terikat oleh waktu dan bukan merupakan suatu kuantitas yang statis. Budaya dapat berubah di mana perubahannya tergantung kepada kekuatan budaya dan intensitas interaksinya dengan budaya lain.

Indonesia memiliki suku dan budaya yang beranekaragam. Hal ini dikarenakan 
pengaruh letak geografis dan etnis. Salah satunya mengangkat etnis Jawa. Etnis Jawa merupakan etnis yang paling dominan karena dilihat dari luas wilayahnya, jumlah populasinya serta budayanya yang beranekaragam. Suku Jawa merupakan suku terbesar di Indonesia yang terdiri dari Jawa Tengah, Daerah Istimewa Yogyakarta, Jawa Timur, Kabupaten Indramayu dan Kabupaten/Kota SerangCilegon. Berdasarkan data Badan Pusat Statistik (BPS) 2010, Suku Jawa menjadi suku terbesar di Indonesia dengan jumlah mencapai $41 \%$ dari total populasi.

Sifat dan kebiasaan orang Jawa menurut Koentjaraningrat (1996) masyarakat adalah kesatuan hidup dari makhluk-makhluk manusia yang terikat oleh suatu sistem adat istiadat. Herusatoto (1987) masyarakat Jawa adalah sebagai salah satu masyarakat yang hidup dan tumbuh berkembang dari zaman dahulu sampai sekarang dan turun-temurun menggunakan bahasa Jawa dalam berbagai ragam dialeknya serta mendiami sebagian besar Pulau Jawa. Suyanto (1990) mengatakan bahwa karakteristik budaya Jawa adalah religius, non doktriner, toleran, akomodatif, dan optimistik. Karakteristik ini membentuk sifat khas masyarakat Jawa antara lain percaya Tuhan Yang Maha Esa, percaya kepada sesuatu yang bersifat immaterial bukan kebendaan, percaya pada hal-hal yang bersifat supernatural bahkan cenderung ke arah mistik, mengutamakan hakikat daripada segi-segi formal dan ritual, mengutamakan cinta kasih sebagai landasan pokok hubungan antar manusia, percaya kepada takdir, cenderung bersikap pasrah, bersifat konvergen dan universal, berani, cerdas, dan pekerja keras, non-sektarian, simbolisme, gotong royong, rukun, damai, kurang kompetitif karena kurang mengutamakan materi.

Ketika bersosialisasi, orang Jawa berusaha untuk tidak mudah marah walau dicaci maki. Cacian, hinaan dan umpatan tidak akan dilawan, justru diterima sebagai koreksi diri untuk meningkatkan kehidupan ke jenjang yang lebih sabar, lebih tenang, dan lebih arif. Orang Jawa meyakini bahwa buah dari kearifan adalah kebahagiaan dan kemuliaan, sedangkan kebahagiaan dan kemuliaan adalah tujuan tertinggi dari hidup (Tartono, 2009).

Bahasa Jawa memiliki tingkatan dan terdiri dari 3 jenis antara lain 1) Ngoko yaitu tingkatan bahasa yang penggunaannya dihindari jika berbicara dengan orang yang lebih tua (dihormati); 2) Kramo yaitu tingkatan bahasa yang penggunaannya sangat baik jika berbicara dengan orang yang lebih tua (dihormati); 3) Madya yaitu tingkatan bahasa yang merupakan campuran Ngoko dan Krama, 
serta Bagongan yaitu bahasa khusus istana.

Semiotika merupakan studi mengenai tanda (sign) dan simbol yang menjadi hal penting dalam komunikasi (Morissan, 2013). Semiotika meliputi tanda mewakili objek, ide, situasi, keadaan, perasaan yang berada di luar diri. Mempelajari komunikasi, tanda tidak hanya menjadi cara tetapi memiliki pengaruh pada setiap aspek yang digunakan pada teori komunikasi. Ilmu mengenai tanda pertama kali diperkenalkan oleh Charles Sanders Peirce.

Peirce menjelaskan ilmu tanda merujuk pada penggunaan tanda pada bahasa yaitu makna yang tercantum di dalam bahasa. Peirce menyebut teorinya sebagai grand theory dalam semiotika karena bersifat menyeluruh, penjelasannya terstruktur dari semua penandaan (Wibowo, 2013). Peirce mengidentifikasi dasar-dasar dari sebuah tanda dan menggabungkan kembali semua komponen yang ada dalam konsep triadic antara lain 1) Representamen/Tanda (Sign): Bentuk fisik yang diterima panca indera mengacu pada sesuatu yang memiliki fungsi sebagai tanda. Sign meliputi Qualisign (Tanda berdasarkan sifatnya), Singsign (Tanda yang sesuai bentuk kenyataan), Legisign (Tanda sebagai peraturan yang berlaku); 2) Objek: merujuk pada tanda. Objek meliputi Icon (tanda memiliki kesamaan dengan objek yang dimaksud), Index (tanda yang mempunyai hubungan sebab akibat), Symbol (tanda berdasarkan kesepakatan bersama); 3) Interpretan: Mengacu pada makna dari tanda. Interpretan meliputi Rhema (Lambang dan makna tanda dapat dikembangkan), Decisign (Lambang dan interpretan terdapat hubungan yang benar), Argument (lambang dan tanda memiliki sifat umum) (Wibowo, 2013).

\section{METODE PENELITIAN}

Penelitian ini menggunakan pendekatan kualitatif yakni menafsirkan fenomena yang terjadi kemudian dilakukan dengan berbagai metode seperti wawancara, studi kepustakaan dan penggunaan dokumen-dokumen yang relevan yang dikumpulkan berupa teks film. Langkah pertama yang dilakukan adalah pemilihan teks dan gambar yang berhubungan dengan budaya Jawa dengan mengamati secara keseluruhan film, kemudian peneliti menganalisis data yang telah terkumpul. Peneliti menggunakan metode semiotika Charles Sanders Pierce yaitu analisis tentang tanda dengan menggunakan tiga jenis tanda yaitu ikon, indeks dan simbol untuk menemukan kearifan lokal budaya Jawa yang digambarkan di dalam film. Data-data tersebut kemudian ditafsirkan dengan 
referensi serta sumber yang berkaitan dengan penelitian. Narasumber sekaligus yang menjadi subjek penelitian ini adalah pengamat budaya Jawa yang merupakan staf pengajar kesenian yaitu Mateus Suwarsono S.Sn. Peneliti menggunakan analisis triangulasi data dengan sumber dan metode untuk menguji keabsahan data. Menurut Patton (Pujileksono, 2015) dengan menggunakan teknik triangulasi sumber, peneliti membandingkan hasil wawancara yang diperoleh dari sumber informan kunci sebagai pembanding untuk memeriksa keabsahannya. Teknik pengumpulan data melalui wawancara dengan narasumber ahli sehingga derajat kepercayaan data dapat terverifikasi dengan baik.

\section{HASIL DAN PEMBAHASAN}

\section{Kearifan Lokal Tilik}

Film ini berkisah tentang perjalanan ibu-ibu di satu desa menjenguk Bu Lurah yang sedang sakit di rumah sakit dimana memperlihatkan dinamika dan sebuah percakapan warga. Pemaparan melalui karakterwanita (ibuibu) dalam kehidupan masyarakat pada umumnya yang suka memberi prasangka terhadap sebuah informasi yang valid. Kegiatan menjenguk (Tilik) yang digambarkan di dalam film merupakan kebudayaan dan tradisi masyarakat Jawa yang hingga hari ini masih berkembang dan menjadi kearifan lokal yang masih dilestarikan serta hampir menyebar di seluruh wilayah Jawa Tengah, Daerah Istimewa Yogyakarta dan Jawa Timur.

Sibarani (2012) kearifan lokal merupakan suatu bentuk pengetahuan orisinil dalam masyarakat yang berasal dari nilai luhur budaya masyarakat setempat untuk mengatur tatanan kehidupan masyarakat ataupun dikatakan bahwa kearifan lokal. Kearifan lokal sebagai bentuk kebijaksanaan yang didasari oleh nilai-nilai kebaikan yang dipercaya, diterapkan dan senantiasa dilestarikan dalam kurun waktu secara turun-temurun oleh sekelompok orang ataupun wilayah tempat tinggal mereka.

Hal tersebut bisa tercipta dalam pola pikir masyarakat yang memiliki budi pekerti baik, cinta tanah kelahiran, bentuk perangai/tabiat masyarakat kebanyakan pada kawasan tertentu yang tetap menempel dan dibawa ketika berbaur dengan kelompok masyarakat/lingkungan yang berbeda, filosofi hidup masyarakat tertentu yang mendarah daging dan tetap lekat walaupun telah using hidup di perantauan serta kemauan besar untuk tetap menjalankan adat/tradisi yang telah using diikuti secara turun temurun.

Kamus Besar Bahasa Indonesia, Tilik artinya penglihatan yang teliti, sinar 
(pandangan) mata, tenung, teluh, yang memiliki kata turunan menjadi menilik. Menilik berarti melihat dengan sungguhsungguh, mengamat-amati, mengawasi, memeriksa, melihat, memandang, menganggap, melihat (meninjau) dari dan menjenguk. Tilik merupakan aktivitas menjenguk orang sakit, takziah ke tempat orang meninggal, mengunjungi bayi yang baru lahir serta mengunjungi teman/saudara yang kembali dari menunaikan ibadah haji, dimana tujuannya adalah memperkuat dan menjaga silaturahmi.

Tilik merupakan budaya untuk mengajak masyarakat untuk saling perduli dan berbagi kepada sesama yang telah menjadi budaya gotong royong serta budaya guyub masyarakat yang sudah mengakar terutama di masyarakat pedesaan di Jawa. Hal ini menjadi dukungan kuat tradisi lokal turun temurun dari generasi ke generasi. Semakin tinggi strata seseorang yang akan dijenguk, maka semakin besar jumlah orang yang datang menjenguk. Tilik akan tetap dilestarikan selama masyarakat di pedesaan masih memegang nilai luhur serta norma yang masih berkembang. Solidaritas antar warga semakin menumbuhkan rasa persatuan serta kesatuan yang mendukung terjalinnya kerukunan sehingga warga tetap kompak dalam melakukan kebaikan.

\section{Analisis Triadic Pierce}

Film berdurasi 32 menit ini menunjukkan secara visual fenomena sekelompok ibu-ibu dari pedesaan di pinggiran Yogyakarta yang dipenuhi dengan dialog serta gosip di atas truk sehingga terdapat pesan yang tersembunyi mengenai representasi wanita dan kearifan lokal suku Jawa.

Tabel 1 : Analisis Triadic Pierce Ibu-Ibu Pergi Menjenguk (Tilik) Bu Lurah dengan Menaiki Truk Representame Ibu-Ibu di atas Truk $\mathrm{n} /$ Tanda Objek
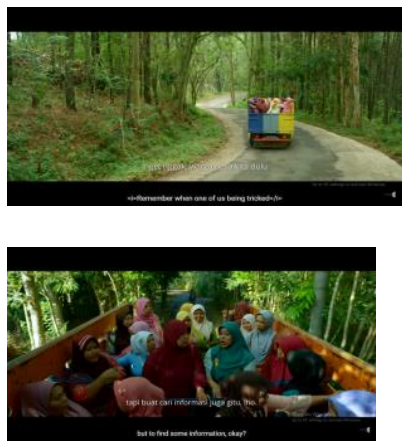

Interpretant Budaya masyarakat khususnya Jawa tentang gotong royong, tolong menolong, ketika berpergian selalu berjanjian, pergi secara rombongan, tidak terhalang sekalipun jaraknya agak jauh, menaiki truk yang menjadi alat transportasi jika ingin berpergian beramairamai walau truk cenderung digunakan untuk mengangkut barang karena untuk menyewa bis akan dikenakan biaya dan di desa tidak banyak yang memiliki mobil pribadi. Terkandung 


pesan simbolik bahwa
masyarakat Jawa
menghargai
budayanya dalam
kehidupan sehari-hari
dari kebiasaan
mengerjakan sesuatu
bersama-sama,
memperlihatkan
kekuatan keguyuban
antar warga menjaga
persatuan dan
kesatuan.

Sumber Tabel : Diolah oleh Penulis

Kuatnya solidaritas sosial masyarakat disebabkan karena terdapat ciri-ciri sosial ekonomi, budaya, dan tujuan hidup yang sama serta diimbangi dengan kontrol sosial melalui normanorma dan nilai-nilai yang ditetapkan di masyarakat.

Seperti budaya Indonesia secara umum, budaya Jawa cenderung kolektif. Budaya yang kolektif perilaku dari anggotanya sangat ditentukan oleh keanggotan kelompok dan kebersamaan dan harmoni (Masturi, 2015). Budaya kolektif yang diperlihatkan dalam masyarakat Jawa menggambarkan konsep sosial yang kuat karena perbedaan antara di dalam kelompok dan luar kelompok (Hofstede, 1980) di mana di dalam masyarakat kolektif kualitas kehidupan yang tinggi didefenisikan lebih pada hubungan kekeluargaan dan di dalam kelompok.
Tabel 2 : Analisis Triadic Pierce Solidaritas Menyumbangkan Uang

\begin{tabular}{llr}
\hline Representamen/ & Ketika truk yang \\
Tanda & dikendarai Gotrek keluar \\
& dari kampung, dimana Yu \\
& Ning bertugas sebagai \\
& kordinator mengatur \\
& persiapan menjenguk Bu \\
& Lurah, mengkonfirmasi \\
& kepada ibu-ibu yang lain \\
& untuk menyumbang \\
& tanpa memandang siapa \\
& yang menyumbang dan \\
& tidak melihat berapa \\
& jumlah yang akan \\
& disumbangkan. Yu Ning \\
& juga meminta ibu-ibu \\
& menjadi saksi saat dia \\
& memasukkan uang \\
& tersebut ke dalam \\
& amplop. \\
&
\end{tabular}

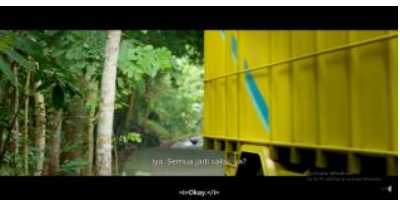

Dialog

Yu Ning : Sudah semua ini? Aku masukin amplop ya?

Ibu-ibu : Iya

Yu Ning : Semua jadi saksi ya?

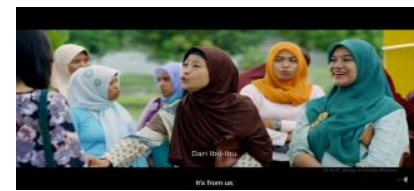

Dialog

Yu Ning : Dari Ibu-ibu

Fikri : Duh jadi merepotkan

Yu Ning : Tidak apa-apa diterima saja. Semoga ibu lekas sembuh

Interpretant Tradisi masyarakat pedesaan dalam interaksi sosialnya yang lebih intensif menjunjung kekompakkan, transparan, peduli, 
solidaritas serta memiliki ikatan kekeluargaan yang sangat kuat. Tidak melihat seberapa besar jumlah sumbangan yang akan diberikan, namun lebih memperlihatkan rasa empati menjenguk kerabat yang sedang sakit. Jika dibandingkan dengan masyarakat di perkotaan, budaya Tilik mulai tergerus dan perlahanlahan ditinggalkan. Dengan kepesatan teknologi, kegiatan Tilik sudah cukup terwakilkan dengan video call.

Sumber Tabel : Diolah oleh Penulis

Tabel 3 : Analisis Triadic Pierce Percakapan/Dialog Bahasa Jawa
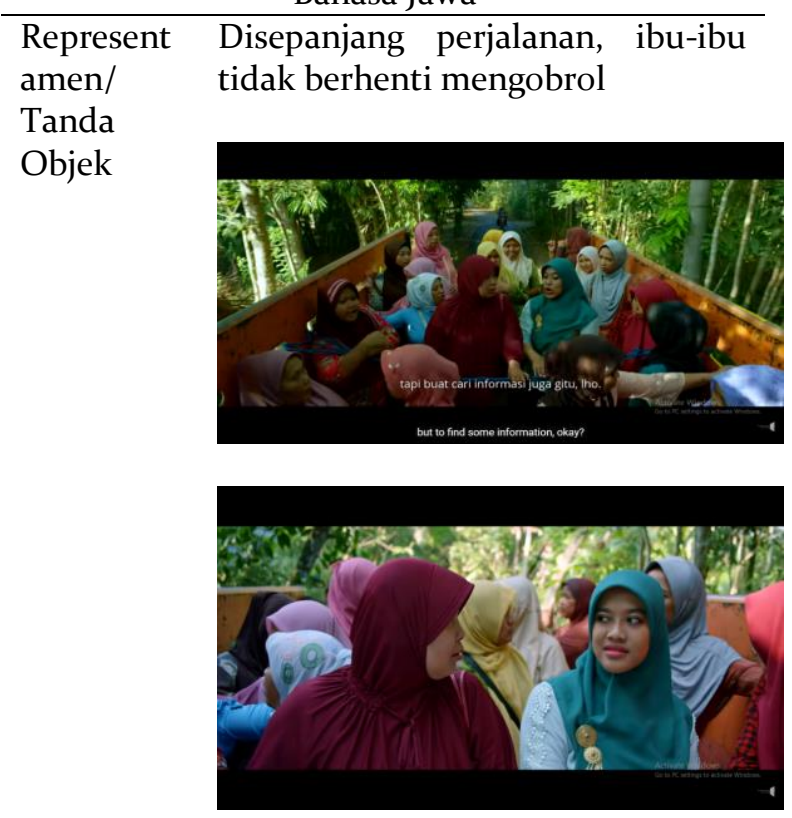

Interpreta Penggunanaan bahasa Jawa di nt seluruh dialog memperlihatkan bahwa komunikasi dan interaksi warga desa masih sangat kuat. Komunikasi yang bersifat personal terjadi di antara satu warga dengan warga lainnya.

Sumber Tabel : Diolah oleh Penulis

Akhirnya $\mathrm{Bu}$ Lurah tidak dapat dijenguk, namun ibu-ibu yang lain tidak kecewa. Mereka tetap senang karena bisa turut serta saja sudah cukup, naik kendaraan apa saja tidak masalah, yang terpenting dapat sampai di lokasi dan mengetahui bahwa kabar Bu Lurah baikbaik saja. Situasi ini memperjelas bahwa sangat mudah mengajak warga meluangkan waktunya ikut serta bersama warga lainnya menjenguk warga yang sakit karena bisa saja suatu saat mereka bergantian sakit. Rasa simpati dan empati pun menumbuhkan kerukunan di dalam masyarakat. Sanksi sosial dapat terjadi secara tidak langsung bagi warga yang tidak berpartisipasi dalam kegiatan sehingga menjadi kontrol sosial yang sifatnya otomatis. Masyarakat, terdapat nilai-nilai yang terlihat dalam perilaku nyata, kerana nilai memberikan arahan dalam pengambilan keputusan serta perilaku. Budaya Jawa, terdapat nilai-nilai yang diajarkan seperti nilai kerukunan, jujur, teposliro, sopan santun, elinglan waspodo, sabar sareh narimo, tulung tinulung, andap asor, prasojo dan sebagainya (Lestari 2016).

Manfaat dari Tilik bagi orang yang sakit dapat menumbuhkan semangat untuk lekas pulih sehingga dapat berkumpul kembali dengan keluarga dan warga. Sementara bagi yang menjenguk, dapat menambah karunia dan rasa syukur kesehatan dari Tuhan. Dengan menjenguk orang sakit, sangat jelas 
memperlihatkan solidaritas sosial dan sikap kolektif.

Tabel 4 : Nilai Budaya Jawa dalam Berhubungan dengan Sesamanya

$\begin{array}{ll}\text { Repres } & \text { Fikri menjumpai ibu-ibu di halaman } \\ \text { entam } & \text { parkir dan langsung menyalam Yu } \\ \text { en/ } & \text { Ning }\end{array}$

Tanda

Objek

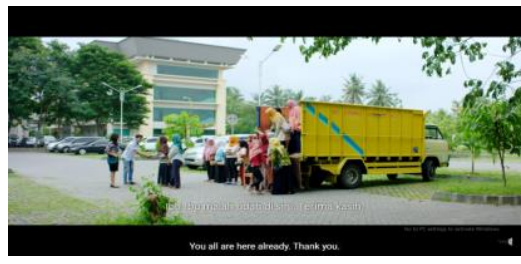

Interpr Kebiasaan masyarakat Jawa etant bersalaman baik ketika bertemu atau berpamitan, serta berbicara dengan sikap sopan santun. Tata karma dikenal dengan istilah unggah ungguh di dalam budaya Jawa

\section{Sumber Tabel : Diolah Oleh Penulis}

Tabel 5 : Tidak Ada Perbedaan Kelas Ketika Menaiki Truk

$\begin{array}{ll}\begin{array}{l}\text { Representame } \\ \mathrm{n} / \text { Tanda }\end{array} & \begin{array}{l}\text { Ibu-Ibu jongkok ketika } \\ \text { mendengar klakson (aba-aba) } \\ \text { dari Gotrek }\end{array} \\ \text { Objek } & \end{array}$

Interpretant

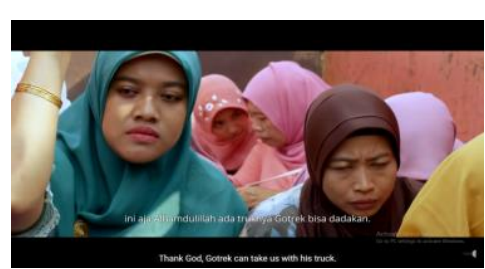

Gotrek memiliki semiotika budaya yang khas yakni kode membunyikan klakson dua kali untuk memberitahu ibuibu agar duduk/jongkok, dan membunyikan klakson satu kali untuk memberitahu ibuibu boleh boleh berdiri yang tujuannya agar tidak ditilang polisi. Kekompakan ketika menaiki truk memperlihatkan tidak ada perbedaan yang memandang kasta. Semuanya sama, berdiri dan duduk di atas truk.

\section{Sumber Tabel : Diolah oleh Penulis}

Tabel 6 : Cultural Proximity (Kedekatan Budaya) Sebagai Fenomena Yang Masih Sering Terjadi Di Keseharian Masyarakat 1

\begin{tabular}{ll}
\hline $\begin{array}{l}\text { Representamen// } \\
\text { Tanda }\end{array}$ & $\begin{array}{l}\text { Salah seorang Ibu mabuk } \\
\text { kendaraan. Ibu-Ibu yang lain } \\
\text { sibuk meminta plastik, } \\
\text { mengelurkan minyak kayu } \\
\text { putih dan kulit jeruk }\end{array}$ \\
Objek & \\
& \\
Interpretant & $\begin{array}{l}\text { Menghirup minyak kayu } \\
\text { putih dan kulit jeruk } \\
\text { dipercayai mas marakat } \\
\text { mampu mengurangi rasa } \\
\text { mabuk perjalanan dan } \\
\text { masuk angin }\end{array}$ \\
\hline
\end{tabular}

Sumber Tabel : Diolah oleh Penulis

Tabel 7 : Cultural Proximity (Kedekatan Budaya) Sebagai Fenomena Yang Masih Sering Terjadi Di Keseharian Masyarakat 2

\begin{tabular}{ll}
\hline $\begin{array}{l}\text { Representamen/ } \\
\text { Tanda }\end{array}$ & $\begin{array}{l}\text { Bu Tedjo ingin buang } \\
\text { air kecil dan Yu Ning } \\
\text { memberinya karet }\end{array}$ \\
Objek & \\
& $\begin{array}{l}\text { Dialog } \\
\text { Yu Ning : nih, nih } \\
\text { jempolnya dikaretin } \\
\text { dulu biar tidak kebelet } \\
\text { Pada dasarnya karet } \\
\text { gelang hanya alat } \\
\text { untuk membantu } \\
\text { pekerjaan ikat } \\
\text { mengikat, namun } \\
\text { masih dipercayai } \\
\text { masyarakat bahwa }\end{array}$ \\
& \multicolumn{2}{c}{ interpretant }
\end{tabular}




\begin{tabular}{ll}
\hline & karet gelang yang \\
& diikatkan pada jempol \\
& kaki dapat menahan \\
& keinginan untuk \\
buang air kecil & \\
\hline
\end{tabular}

Sumber Tabel : Diolah oleh Penulis

Tabel 8 : Cultural Proximity (Kedekatan Budaya) sebagai Fenomena yang Masih Sering Terjadi di Keseharian Masyarakat 3

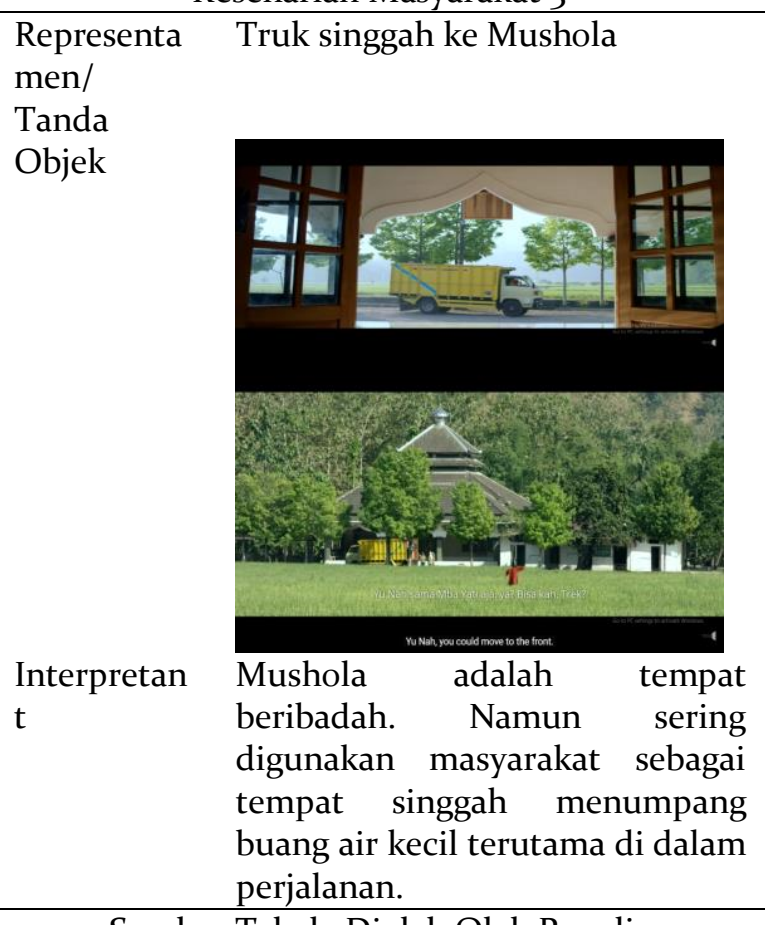

Sumber Tabel : Diolah Oleh Penulis

Tabel 9: Setting Lokasi

Representamen/
Tanda
Objek
Interpretant
Keindahan Yogyakarta
kecamatan Dlan
Bantul, Yogyakarta
terlihat dari suasana
jalan yang dilewati
truk, keindahan hutan
dan sawah

Sumber Tabel : Diolah oleh Penulis
Film menggambar representasi wanita tergambar senang bergosip menceritakan Dian si kembang desa. Bergosip dan berghibah mungkin adalah cara untuk menghilangkan tekanan serta cara untuk mengisi waktu luang dengan tetangga yang menjadi realitas seharihari. Gosip biasanya terdiri dari cerita yang ditujukan untuk merusak reputasi seseorang atau beberapa orang yang dapat dikenali. Seandainya pelakunya tidak disebutkan namanya dan korbannya disebutkan dengan jelas, dapat dikatakan ada semacam suara demokrasi terselubung mengenai gosip dalam arti gosip hanya disebarkan sejauh orang lain merasa tertarik untuk menceritakan kembali cerita tersebut jika tidak, cerita itu akan menghilang (James C Scott, 1990).

$$
\text { Temuan yang diperoleh }
$$

berdasarkan dari hasil wawancara dengan narasumber adalah film Tilik lebih mencerminkan sosial kultural (interaksi sosial) dimana budaya Tilik menjadi bagian dari kebudayaan mangan oramangan kumpul maksudnya masyarakat Jawa senang berkumpul walau tidak ada makan (kondisi sebenar keadaan susah) untuk tujuan memperkuat silaturahmi (saling menguatkan). Tilik dapat diartikan menjenguk orang sakit, orang tua, bayi 
yang baru lahir, orang pulang haji dimana berdasarkan prinsip adigang adigung adiguna (menggunakan kekuatan, kekuasan dan kepandaian) yang bermakna manusia hendaknya tidak mengandalkan dan menyombongkan kelebihan yang dia miliki sehingga cara memperlakukan keluarga ataupun orang lain adalah sama (tidak dibedakan). Walau yang dijenguk misalnya anak buah sendiri atau asisten rumah tanggasendiri, tidak ada pilih kasih (emban cindhe emban siladan).

Budaya naik truk masih ada karena orang Jawa memiliki filosofi hidup gemi nastiti ngati-ati yaitu gemi (irit/hemat), nastiti (teliti), ngati-ati (waspada). Seandainya kita memiliki suatu pekerjaan, kalau bisa ditanggung bersama kenapa harus sendiri-sendiri? Menjenguk orang sakit apabila dilakukan sendiri-sendiri maka akan mengeluarkan biaya yang lebih besar. Dengan menaiki truk, akan menjadi lebih murah (pembayaran akan dibagi ke beberapa orang). Budaya naik truk ini juga masih dilestarikan hampir di seluruh wilayah Jawa yang mengenal bahasa Jawa terutama di pedesaan. Hal ini merupakan prinsip guyub rukun sebagai bagian gotong royong, tulung tinulung sebagai bentuk efisiensi serta ekonomis yang menjadi cirri khas masyarakat di pedesaan.

Tradisi mengobrol memang hampir dilakukan sebagian besar kaum wanita (ibu-ibu) misalnya ketika melakukan aktivitas mencari kutu, mencuci bersama-sama, dimana hal ini menjadi sebuah warna, tidak sekedar untuk konotasi negatif (bergosip/bergunjing). Sisi positif pada dasarnya bercerita merupakan sebuah bentuk perhatian untuk berbagi informasi (misalnya berbagi informasi ada kerabat yang sakit, suami si A naik pangkat), yang positif akan menanggapi berita tersebut dengan positif dan yang negatif akan menanggapinya secara negatif. Hal tersebut sesuai di dalam film dimana ada dua sisi yang dibenturkan berdasarkan realitas yang memang terjadi. Berdasarkan film lebih menguatkan sisi yang negatif (pergunjingan) dengan tujuan agar film tersebut menjadi lebih sexy.

Penggunaan bahasa Jawa di dalam film menggunakan ngoko. Orang yang berada di strata paling bawah (ngoko) wajib menguasai kromo dengan baik terlebih dahulu karena prinsipnya kepada siapa saja harus bisa berbahasa halus. Hubungan jika sudah akrab, baru boleh ngoko, untuk strata paling atas boleh ngoko dengan siapa saja. Pemaparan suku Jawa di dalam film sudah sesuai karena 
menggunakan dialog Jawa medhok.

Karakter

ibu-ibu

yang

menghadang polisi lalu-lintas dan

karakter $\mathrm{Bu}$ Tedjo agak berlebihan divisualkan, tapi menurut narasumber hal tersebut hanya untuk kebutuhan dramatik film karena realitasnya karakter seperti Bu Tedjo pasti ada di masyarakat terutama dalam hal menanggapi gosip yaitu ada yang menanggapi secara positif dan negatif. Film ini menggambarkan bahwa lumrahnya wanita adalah senang mengobrol. Dahulu wanita rumahan di Jawa disebut Konco Wingking (Konco Istri) tugasnya hanya di dapur dan kamar tidur, maka untuk dapat menghilangkan kepenatan kesehariannya mengobrol adalah ruang bagi wanita.

Karakter Dian yang menjadi simpanan Pak Lurah di dalam film, merujuk sejarah wanita di tradisi ranah bangsawan terdapat selir dan gundik. Pak Lurah disimbolkan sebagai pejabat/bangsawan/raja, hubungan resmi dan tidak resmi seperti ini memang tetap ada karena hal ini sudah menjadi fenomena umum. Bagi wanita Jawa yang belum atau terlambat menikah tidak ada konotasi negatif sama sekali dan justru kerabat terdekatnya yang berusaha mencarikan jodohnya. Hal ini sama seperti yang berlaku di suku Batak dengan mencarikan paribannya.

\section{SIMPULAN}

Tilik merupakan warisan asli budaya Jawa yang mengangkat pola keseharian masyarakat Indonesia pada umumnya. Inti dari Tilik yaitu saling menguatkan satu sama lainnya dan merekatkan kembali silaturahmi yang kadang sudah renggang oleh kata dan suara. Film, tergambar dari kebiasaan yang sering dihadapi oleh masyarakat dalam kesehariannya. Tilik orang sakit biasanya dilakukan bersamasama, sudah menjadi tradisi kehidupan terutama warga desa yang masih diwariskan seandainya ada salah satu warga yang sakit maka salah satu tetangga terdekat akan memberitahu kepada tetangga yang lain untuk kemudian menentukan waktu, mencari informasi tentang kondisinya, apabila lokasinya jauh dan akan bergotong royong menyewa kendaraan untuk menjenguk warga yang sakit dengan memberikan sedikit uang untuk meringankan biaya berobat keluarga yang sedang sakit. Budaya yang dilakukan ibu-ibu Jawa ini sebagai bentuk toleransi serta rasa kebersamaan antar warga melalui sikap teposliro. Budaya menaiki truk sebagai angkutan tidak hanya terdapat di dalam film, tetapi juga terjadi di dalam kehidupan sehari-hari karena tradisi ini masih dapat dijumpai di daerah Bantul, Daerah Istimewa Yogyakarta dan di beberapa daerah di Indonesia lainnya 
(Sumatera Barat, Tanah Karo, Perbaungan dan lain-lain) di mana truk digunakan warga untuk pergi berlibur beramai-ramai, bertamasya bahkan menghadiri resepsi pernikahan. Pemaparan simbol Jawa terlihat dari karakter pemeran film, setting keindahan alam Kecamatan Dlingo, Bantul, Yogyakarta, suasana jalan raya yang dilewati truk, keindahan sawah, serta Jawa Ngoko masyarakat desa sangat terasa melalui dialog yang digunakan di dalam keseluruhan film namun terdapat nilainilai budaya yang dikonstruk dan diproduksi sehingga memberikan penilaian bahwa pemaparan wanita Jawa yang disajikan di dalam film sedikit berlebihan menjadi proses penandaan, praktik yang membuat suatu hal menjadi memiliki makna.

\section{UCAPAN TERIMAKASIH}

Peneliti mengucapkan terimakasih kepada Mateus Suwarsono S.Sn selaku pengamat budaya Jawa sekaligus staf pengajar kesenian yang telah bersedia menjadi narasumber untuk bekerjasama selama proses penelitian berlangsung.

\section{DAFTAR PUSTAKA}

Alfian, Magdalia. (2013). Potensi Kearifan Lokal Dalam Pembentukan Jati Diri dan Karakter Bangsa, Proceeding The 5th International Conference on Indonesia Studies: Ethnicity and Globalization, Jakarta.

Danesi, Marcel. (2010). Pengantar Memahami Semiotika Media. Yogyakarta: Jalasutra.

Hall, Stuart. (2002). Representation. London, Thousand Oaks, New Delhi: Sage Publication.
Hofstede, Geert. (1980). Culure's Consequences, International Differences In Work Related Values. Sage Publications, Beverly Hills, London.

Koentjaraningrat. (1996). Pengantar Ilmu Antropologi. Jakarta: AksaraBaru.

Lestari, Rini. (2016). Transmisi Nilai Prososial Pada Remaja Jawa. Jurnal Indegenous Vol 1 No 2. 2016:33-34.

Masturi, M. 2015. Counselor Encapsulation: Sebuah Tantangan dalam Pelayanan Konseling Lintas Budaya. Jurnal Konseling Gusjigang, 1(2).

Morissan. (2013). Teori Komunikasi: Individu Hingga Massa. Jakarta: Kencana Prenada Media Group.

Pujileksono, Sugeng.

(2015). MetodePenelitianKomunikasiKualitatif. Malang: Intrans Publishing.

Scott James. (1990). Domination and the Arts of Resistance: Hidden Transcripts. Yale University Press.

Stuart. (1997). Representation: Cultural Representations and Signifying Practices. London: Sage Publications Ltd Hawkes.

Suwarsono, Mateus. (2021, Juli) WawancaraPribadi.

Suyanto. (1990). Pandangan Hidup Jawa. Semarang: Dahana Prize.

Wibowo, IndiawanSeto Wahyu. (2013). SemiotikaKomunikasi. Aplikasi Praktis Bagi Penelitian dan Skripsi Komunikasi. Jakarta: Mitra Wacana Media. 